nephron

Experimental

Nephrology

and Genetics
Nephron 2019;142:147-157

DOI: $10.1159 / 000497117$
Received: November 26, 2018

Accepted after revision: January 20, 2019

Published online: February 6, 2019

\title{
Low Sodium Diet Decreases Stone Formation in Genetic Hypercalciuric Stone-Forming Rats
}

\author{
Nancy S. Krieger ${ }^{a}$ Marc Grynpas ${ }^{b}$ Amy VandenEynde ${ }^{b} \quad J o h n$ R. Asplin ${ }^{c}$ \\ Kevin K. Frick ${ }^{a}$ Min Ho Kim ${ }^{a}$ Felix M. Ramos ${ }^{a}$ Ignacio Granjac \\ David A. Bushinsky ${ }^{a}$ \\ a Division of Nephrology, Department of Medicine, University of Rochester School of Medicine and Dentistry, \\ Rochester, NY, USA; b Lunenfeld-Tanenbaum Research Institute, Mount Sinai Hospital, Toronto, ON, Canada; \\ 'Litholink Corporation, Laboratory Corporation of America ${ }^{\circledR}$ Holdings, Chicago, IL, USA
}

\section{Keywords}

Nephrolithiasis · Sodium · Mineral metabolism

\begin{abstract}
Background: Urine (u) calcium (Ca) excretion is directly dependent on dietary sodium ( $\mathrm{Na}$ ) intake leading to the recommendation for Na restriction in hypercalciuric kidney stone formers. However, there is no direct evidence that limiting $\mathrm{Na}$ intake will reduce recurrent stone formation. Materials and Methods: We used genetic hypercalciuric stone-forming (GHS) rats, which universally form Ca phosphate $(P)$ kidney stones, fed either a low $\mathrm{Na}(\mathrm{LNa}, 0.05 \%)$ or normal $\mathrm{Na}$ (NNa, 0.4\%) Na diet (D) for 18 weeks. Urine was collected at 6-week intervals. Radiographic analysis for stone formation and bone analyses were done at the conclusion of the study. Results: Mean uCa was lower with $\mathrm{LNaD}$ than $\mathrm{NNaD}$ as was
\end{abstract}

\section{KARGER}

(c) 2019 S. Karger AG, Basel

E-Mail karger@karger.com

www.karger.com/nef
$\mathrm{UP}$ and $\mathrm{LNaD}$ decreased mean $\mathrm{uNa}$ and $\mathrm{uChloride.} \mathrm{There}$ were no differences in urine supersaturation (SS) with respect to calcium phosphate ( $\mathrm{CaP}$ ) or Ca oxalate (CaOx). However, stone formation was markedly decreased with LNaD by radiographic analysis. The $L N a D$ group had significantly lower femoral anterior-posterior diameter and volumetric bone mineral density (vBMD), but no change in vertebral trabecular vBMD. There were no differences in the bone formation rate or osteoclastic bone resorption between groups. The LNaD group had significantly lower femoral stiffness; however, the ultimate load and energy to fail was not different. Conclusion: Thus, a low Na diet reduced uCa and stone formation in GHS rats, even though SS with respect to $\mathrm{CaP}$ and $\mathrm{CaOx}$ was unchanged and effects on bone were modest. These data, if confirmed in humans, support dietary Na restriction to prevent recurrent Ca nephrolithiasis.

() 2019 S. Karger AG, Basel 


\section{Introduction}

Hypercalciuria (IH) is the most common metabolic abnormality observed in patients with calcium (Ca)based kidney stones, the most prevalent stones formed by patients in the United States [1,2]. Increased levels of urine (u) Ca increase the probability of growth of Ca oxalate $(\mathrm{CaOx})$ and/or $\mathrm{Ca}$ hydrogen phosphate (brushite) crystals into clinically significant stones [1]. Patients with idiopathic $\mathrm{IH}$, defined as excessive $\mathrm{uCa}$ without a demonstrable metabolic cause, generally have normal serum (s) $\mathrm{Ca}$, normal or elevated serum $1,25(\mathrm{OH})_{2} \mathrm{D}_{3}(\mathrm{~s} 1,25 \mathrm{D})$, normal or elevated serum parathyroid hormone (sPTH), normal or low serum phosphate, and low bone mass [1, $3,4]$. IH exhibits a polygenic mode of inheritance $[3,5]$.

The annual incidence of kidney stones in industrialized nations exceeds 1 per 1,000 persons, with a lifetime risk of $\sim 7 \%$ in women and $\sim 11 \%$ in men [6]. After an initial episode of nephrolithiasis $60-80 \%$ of patients form at least one recurrent stone. Several strategies to decrease stone recurrence have been devised, including potassium citrate [7-9], thiazide diuretics [10], and reduction of dietary sodium $(\mathrm{Na})$ [11-16].

The rationale for preventing stone recurrence by limiting dietary Na relies on both Ca transport physiology and clinical studies. Renal Ca transport is $\mathrm{Na}$ dependent [1719]. Clinically, there is an increased risk for kidney stones in women in the highest quintile of $\mathrm{Na}$ intake compared to the lowest quintile [20]. Comparison of a low-Ca diet with a low-Na, low protein, normal-Ca diet over a 5-year period demonstrated that the latter diet was more effective in reducing stone recurrence although the individual contribution of the reduction in dietary $\mathrm{Na}$ could not be determined [21]. In Ca stone-forming patients, the highest $\mathrm{Na}$ intake correlated with the lowest bone mineral density (BMD) [22]. Urinary $\mathrm{Na}$ has been shown to correlate with urinary $\mathrm{Ca}$, suggesting that $\mathrm{Na}$ intake influences IH and stone formation [23].

To examine the effect of a low $\mathrm{Na}$ diet on urine supersaturation (SS), stone formation and bone quality, we utilized a model of human idiopathic $\mathrm{IH}$, the genetic hypercalciuric stone-forming (GHS) rat [24]. GHS rats were generated by selectively inbreeding Sprague-Dawley rats for increased uCa excretion [24]. When fed a standard, ample Ca diet, each GHS rat now consistently excretes over tenfold more uCa than Sprague-Dawley rat controls [24]. The degree of IH has continued to increase with successive generations, although at a much slower rate than with earlier generations. Like patients with IH, GHS rats have normal serum $\mathrm{Ca}$ [25], increased intestinal $\mathrm{Ca}$ ab- sorption [26] and enhanced bone resorption [27], decreased renal tubule Ca reabsorption [28], and normal s1,25D levels $[26,29,30]$ in addition to decreased BMD $[31,32]$. IH is also a polygenic trait in GHS rats [33]. When fed a standard Ca diet, all GHS rats develop kidney stones $[34,35]$ composed of calcium phosphate (CaP) [34, 36-38]. The addition of hydroxyproline to the diet of GHS rats results in $\mathrm{CaOx}$ stone formation [39-41]. In this study, GHS rats were fed either a normal $\mathrm{Na}$ diet $(\mathrm{NNaD}$, $0.4 \%)$ or a low $\mathrm{Na}$ diet ( $\mathrm{LNaD}, 0.05 \%)$. At the end of 18 weeks, urine and blood chemistry, urine SS, stone formation, and bone quality were evaluated.

\section{Materials and Methods}

\section{Study Protocol}

Three-month-old GHS rats from the 98th generation were divided into 2 groups (each $n=12$ ). Both were fed a normal Ca diet $(1.2 \% \mathrm{Ca})$ with either normal $\mathrm{Na}(0.40 \%, \mathrm{NNaD})$ or low $\mathrm{Na}(0.05 \%$, $\mathrm{LNaD})$. $\mathrm{Na}$ content of the $\mathrm{LNaD}$ diet was adjusted with $\mathrm{NaCl}$ to produce $\mathrm{NNaD}$. At weeks 6,12 , and 18 , each rat was weighed and 24 -h urine collected over 4 days. For 2 collections, urine was acidified with $\mathrm{HCl}$; for another 2 collections, urine was collected in thymol. Collections in thymol were used for $\mathrm{pH}$, uric acid (UA), and chloride $(\mathrm{Cl})$ and collections in $\mathrm{HCl}$ were used for all other measurements. Each rat received an intraperitoneal injection of $1 \%$ calcein green at 10 and 2 days prior to sacrifice for dynamic histomorphometry. At 18 weeks, rats were euthanized and blood was collected via cardiac puncture. Kidneys, ureters, and bladders were removed for X-ray imaging in a faxitron, while bones were obtained for histological studies and mechanical testing. Femurs, humeri, and vertebral columns were harvested and frozen at $-20^{\circ} \mathrm{C}$, while the right tibiae were placed in $70 \%$ ethanol and the left tibiae fixed in $10 \%$ neutral buffered formalin for $48 \mathrm{~h}$ and then decalcified in $10 \%$ EDTA. One rat from each group died during the study and therefore was not included (final $n=11$ ). The University of Rochester Committee for Animal Resources approved all procedures.

\section{Urine and Serum Chemistries}

Urine $\mathrm{Ca}$, magnesium, phosphate, ammonium, and creatinine were measured spectrophotometrically using a Beckman CX5 Pro autoanalyzer (Beckman Coulter, Brea, CA, USA). Urine potassium $(\mathrm{K}), \mathrm{Cl}$, and $\mathrm{Na}$ were measured by ion-specific electrodes on the Beckman CX5 and urine $\mathrm{pH}$ using a glass electrode. Urine citrate, oxalate, and sulfate were measured by ion chromatography using a Dionex ICS 2000 system (Dionex Corp., Sunnyvale, CA, USA). All urine solutes were measured at 6, 12, and 18 weeks and a mean value for each time period as well as overall mean value was calculated. Serum $\mathrm{Ca}$ and phosphate were determined colorimetrically (BioVision, Milpitas, CA, USA). sPTH, FGF23, osteocalcin, and propeptide of type 1 collagen (P1NP) were determined by enzyme immunoassay: intact PTH and FGF23 (Immutopics, San Clemente, CA, USA), OC (Alfa Aesar, Tewksbury, MA, USA) and P1NP (Fisher Scientific). All of these methods have been used previously $[31,36,42-44]$. 
Urine SS

With the measured solute excretion, the urinary SS with respect to $\mathrm{CaOx}, \mathrm{CaP}$, and UA solid phases were calculated using the computer program EQUIL2 [45] as we have done previously [37, 39, $44,46,47]$. Ratios of 1 denote a urine at equilibrium, those $>1$ denote SS and those $<1$ denote undersaturation. There is excellent correspondence between calculated and experimentally measured saturation in urine and blood.

\section{Kidney Stone Formation}

The kidneys, ureters, and bladder were removed from each rat en bloc, frozen and imaged in a Faxitron radiography device (Tucson, AZ, USA) to determine extent of kidney stone formation. Three observers blinded to treatment scored all radiographs on a qualitative scale ranging from 0 (no stones) to 4 (extensive stones).

\section{BMD: Dual Energy X-ray Absorptiometry}

Dual energy X-ray absorptiometry with a Lunar PIXImus Bone Densitometer (Lunar GE, Mississauga, Canada) was used to determine tissue density and mineral content of the right femora and L6 vertebrae. The areal BMD, bone mineral content, and bone area were measured.

\section{BMD: Micro-Computed Tomography}

Micro-computed tomography (microCT) with an 1174 compact microCT (Skyscan, Kontich, Belgium) was used to measure volumetric BMD (vBMD) and microarchitecture of the mid-diaphysis of right femurs (cortical bone) and L6 vertebrae (trabecular bone). For vertebrae, density measured was the area between the growth plates, and for femurs, density measured at one millimeter above and below the mid shaft of the bone. Measured parameters include vBMD (Femoral vBMD), anterior-posterior (AP) diameter, trabecular vBMD, bone volume (BV/TV), trabecular number (Tb.N), trabecular thickness (Tb.Th), and trabecular separation (Tb.Sp).

\section{Tissue Level Remodeling}

Tissue-level remodeling was assessed via histomorphometry on both mineralized (undecalcified) and unmineralized (decalcified) bone thin sections. Stained sections are viewed at a high magnification and results quantified using computer software.

\section{Undecalcified Histomorphometry}

Undecalcified histomorphometry differentiates between mineralized and demineralized tissue in bone fixed in $70 \%$ ethanol. Right tibiae sections were used for static and dynamic histomorphometric analysis. Cross-sections of the left distal tibiae were used for back-scattered electron (BSE) microscopy.

\section{Static Histomorphometry}

Sections $(5 \mu \mathrm{m})$ of undecalcified right tibiae were stained with Goldner's Trichrome and quantified using the Bioquant Osteo 11.2.6 MIR software (Bioquant Image Analysis, Nashville, TN, USA). Trabecular bone was analyzed in the proximal tibia metaphysis. Parameters measured include percent BV (BV/TV), percent bone surface (BS/BV), Tb.N, Tb.Sp, Tb.Th, osteoid volume, percent osteoid volume per BV, osteoid surface, percent osteoid surface per BS, and osteoid width.

Low Na Diet Reduces Stones in GHS Rats

\section{Dynamic Histomorphometry}

Sections of calcein labeled undecalcified right tibiae were used for dynamic histomorphometry and quantified using Bioquant Osteo 11.2.6 MIR software (Bioquant Image Analysis). Parameters measured include percent mineralized surface per BS, mineral apposition rate, bone formation rate normalized over BS (BFR/BS), and BFR normalized over BV(BFR/BV).

\section{Decalcified Histology}

Sections $(5 \mu \mathrm{m})$ of decalcified left tibiae were stained for tartrate-resistant acid phosphatase to measure osteoclasts to assess bone resorption and counterstained with acid hematoxylin. Results were quantified using Bioquant Osteo 11.2.6 software. Trabecular bone of proximal tibial metaphysis was analyzed for osteoclast surface (Oc.S), percent Oc.S, number of osteoclasts (N.Oc), and N.Oc per mm Oc.S.

\section{Biomechanical Properties}

Biomechanics of femurs were assessed using an Instron 4465 mechanical testing instrument (Instron, Burlington, Canada) and Labview 5.0 data acquisition software (National Instruments, Austin, TX, USA) to define a load-displacement curve. Ultimate load, stiffness, ultimate displacement, and energy to break were calculated from the load-displacement curve. Data were normalized for specimen geometry to create a stress-strain curve to derive ultimate stress, failure strain, toughness, and Young's modulus.

Three-point bending. Three-point bending was performed on the right femurs to test the strength of the cortical bone.

Vertebral compression. Vertebral compression was measured on excised L6 vertebrae. Vertebral compression does not result in complete fracture; the failure point was determined by an $8-10 \%$ reduction in load.

Femoral neck fracture. The proximal end of the femurs was subjected to femoral neck fracture using an Instron 4465 to test mechanical properties of cortical and trabecular bone combined.

\section{Degree of Mineralization}

BSE microscopy on both undecalcified right tibiae and left distal tibiae cross-section samples was done with a scanning electron microscope (Philips, XL300ESEM, Best, the Netherlands). Images were taken using a solid state BSE detector (FEI Company, Hillsboro, OR, USA).

\section{Statistical Analysis}

Urine analytes, serum values, and stone formation were compared by ANOVA with a conventional computer program (Statistica, StatSoft, Tulsa, OK, USA) and expressed as mean \pm SE. Bone parameters were analyzed using the SPSS Statistics 20 program (SPSS, Chicago, IL, USA) to perform independent-sample $t$ tests and are expressed as mean \pm SD. Significance for all determinations was considered at $p<0.05$.

\section{Results}

\section{Urine Chemistry}

Overall, mean uCa was lower with $\mathrm{LNaD}$ than $\mathrm{NNaD}$ (Table 1) and uCa was reduced in the first two 6-week 


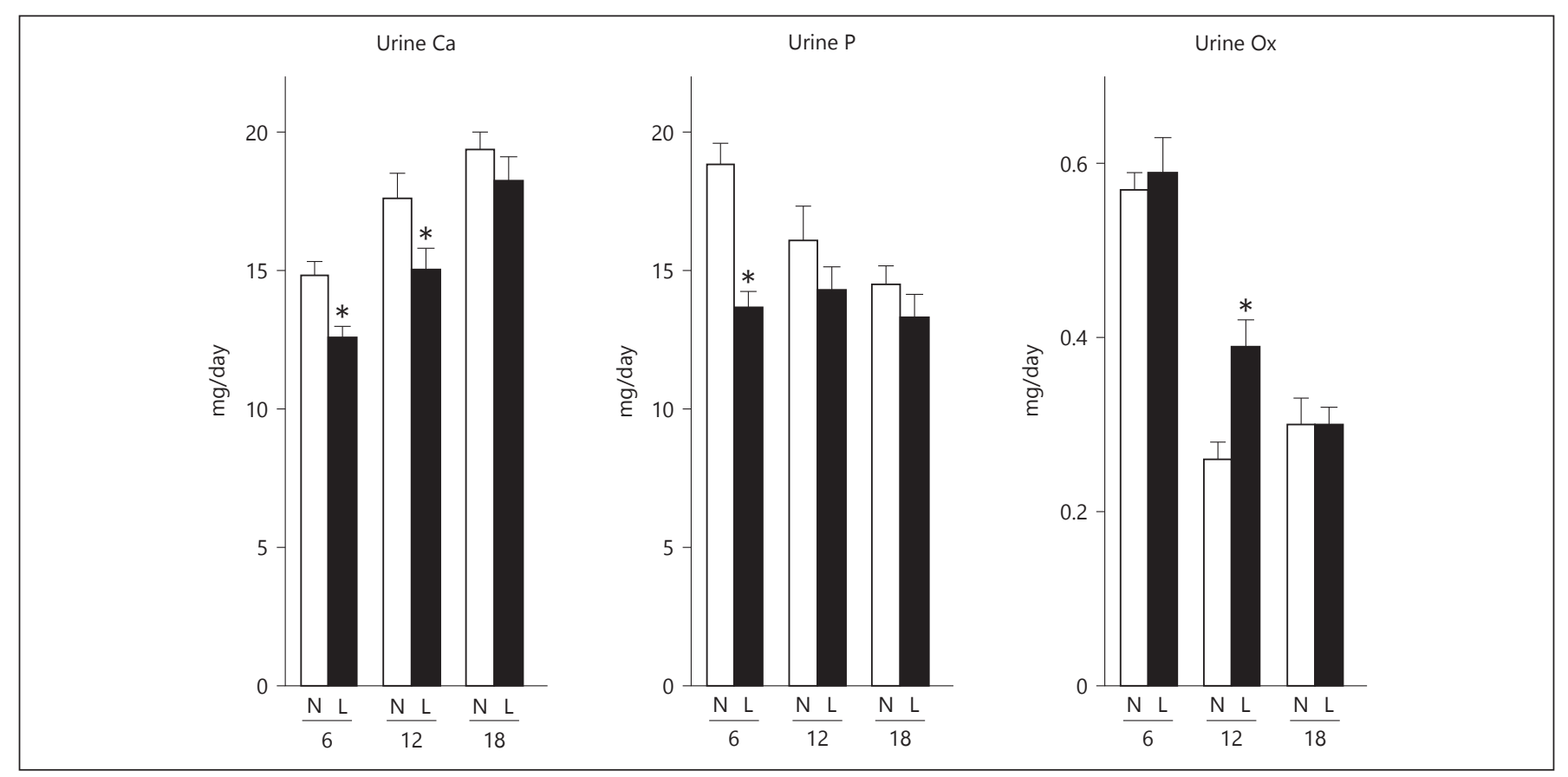

Fig. 1. Urine calcium $(\mathrm{Ca})$, phosphorus $(\mathrm{P})$ and oxalate $(\mathrm{Ox})$ excretion for GHS rats fed a normal (N) or low (L) sodium $(\mathrm{Na})$ diet. Urine was collected for four 24 -h periods at 6,12 , and 18 weeks

Table 1. Overall mean urine parameters

\begin{tabular}{lcc}
\hline Solute & $\begin{array}{l}\text { NNaD, } \\
\text { mean } \pm \mathrm{SD}\end{array}$ & $\begin{array}{l}\text { LNaD, } \\
\text { mean } \pm \mathrm{SD}\end{array}$ \\
\hline $\mathrm{Ca}, \mathrm{mg} /$ day & $17.3 \pm 0.5$ & $15.2 \pm 0.55^{*}$ \\
$\mathrm{P}, \mathrm{mg} /$ day & $16.5 \pm 0.6$ & $13.8 \pm 0.4^{*}$ \\
$\mathrm{CaOx}, \mathrm{mg} /$ day & $0.38 \pm 0.03$ & $0.43 \pm 0.02$ \\
$\mathrm{Na}, \mathrm{mmoL} /$ day & $2.48 \pm 0.04$ & $0.39 \pm 0.02^{*}$ \\
$\mathrm{Cl}, \mathrm{mmoL} /$ day & $2.65 \pm 0.13$ & $1.20 \pm 0.06^{*}$ \\
Potassium, mmoL/day & $1.39 \pm 0.02$ & $1.27 \pm 0.03^{*}$ \\
Citrate, mg/day & $60.24 \pm 1.6$ & $57.24 \pm 1.6$ \\
Ammonium, mmoL/day & $1.07 \pm 0.07$ & $0.96 \pm 0.03$ \\
Magnesium, mg/day & $15.0 \pm 0.3$ & $14.1 \pm 0.3$ \\
Creatinine, mg/day & $11.65 \pm 0.19$ & $11.31 \pm 0.26$ \\
pH & $6.24 \pm 0.07$ & $6.17 \pm 0.08$ \\
Volume, mL & $29.6 \pm 1.1$ & $27.8 \pm 1.5$ \\
UA, mg/day & $1.35 \pm 0.07$ & $1.44 \pm 0.10$ \\
Sulfate, meq/day & $1.28 \pm 0.06$ & $1.22 \pm 0.05$ \\
SS UA & $0.09 \pm 0.01$ & $0.18 \pm 0.03^{*}$ \\
SS CaP & $4.8 \pm 0.4$ & $4.6 \pm 0.5$ \\
SS CaOx & $3.2 \pm 0.2$ & $4.0 \pm 0.4$ \\
Weight, g & $298.0 \pm 2.5$ & $290.3 \pm 2.7^{*}$ \\
\hline
\end{tabular}

$* p<0.05$ compared to the $\mathrm{NNaD}$.

$\mathrm{Na}$, sodium; $\mathrm{NNaD}$, normal $\mathrm{Na}$ diet; $\mathrm{LNaD}$, low $\mathrm{Na}$ diet; $\mathrm{Ca}$, calcium; $\mathrm{P}$, phosphate; $\mathrm{CaOx}$, oxalate; $\mathrm{Cl}$, chloride; $\mathrm{UA}$, uric acid; SS, supersaturation. from GHS rats to determine solute levels as described in the Concise Methods. Values are mean \pm SE for 11 rats in each group. $* p<0.05$ for $\mathrm{L}$ compared to $\mathrm{N}$ at the same time period.

time periods but not in the third (Fig. 1). Overall mean uP was lower with $\mathrm{LNaD}$ than $\mathrm{NNaD}$ and $\mathrm{uP}$ was reduced in the first 6 weeks, but not in the later time periods. Overall mean $\mathrm{u}$ oxalate $(\mathrm{Ox})$ was not different between the 2 groups, though it was increased during the second time period with $\mathrm{LNaD}$. Overall mean $\mathrm{uNa}$ and $\mathrm{uCl}$ were significantly lower in GHS fed $\mathrm{LNaD}$ compared to $\mathrm{NNaD}$ (Table 1) and both were lower during each time period (Fig. 2). Overall mean $\mathrm{uK}$ was lower with $\mathrm{LNaD}$ than $\mathrm{NNaD}$ and $\mathrm{uK}$ was reduced in the first two 6-week time periods but not in the third. Creatinine, $\mathrm{pH}, \mathrm{NH}_{4}{ }^{+}$, citrate, and volume did not differ with diet $\mathrm{Na}$ (Table 1). There were no significant differences in urine supersaturation (SS) with respect to the solid phases of $\mathrm{CaP}$ or $\mathrm{CaOx}$ (Fig. 3). Overall mean urine SS with respect to the solid phase of UA was not different between the groups and far less than one at all times; however, it was increased during the second time period with $\mathrm{LNaD}$.

\section{Stone Formation}

$\mathrm{X}$-rays of excised kidneys and ureters were examined radiographically (representative X-rays, Fig. 4a) and an overall stone formation score determined as we have done previously [44]. Radiographic analysis of kidneys demonstrated a significant decrease in stone formation in 


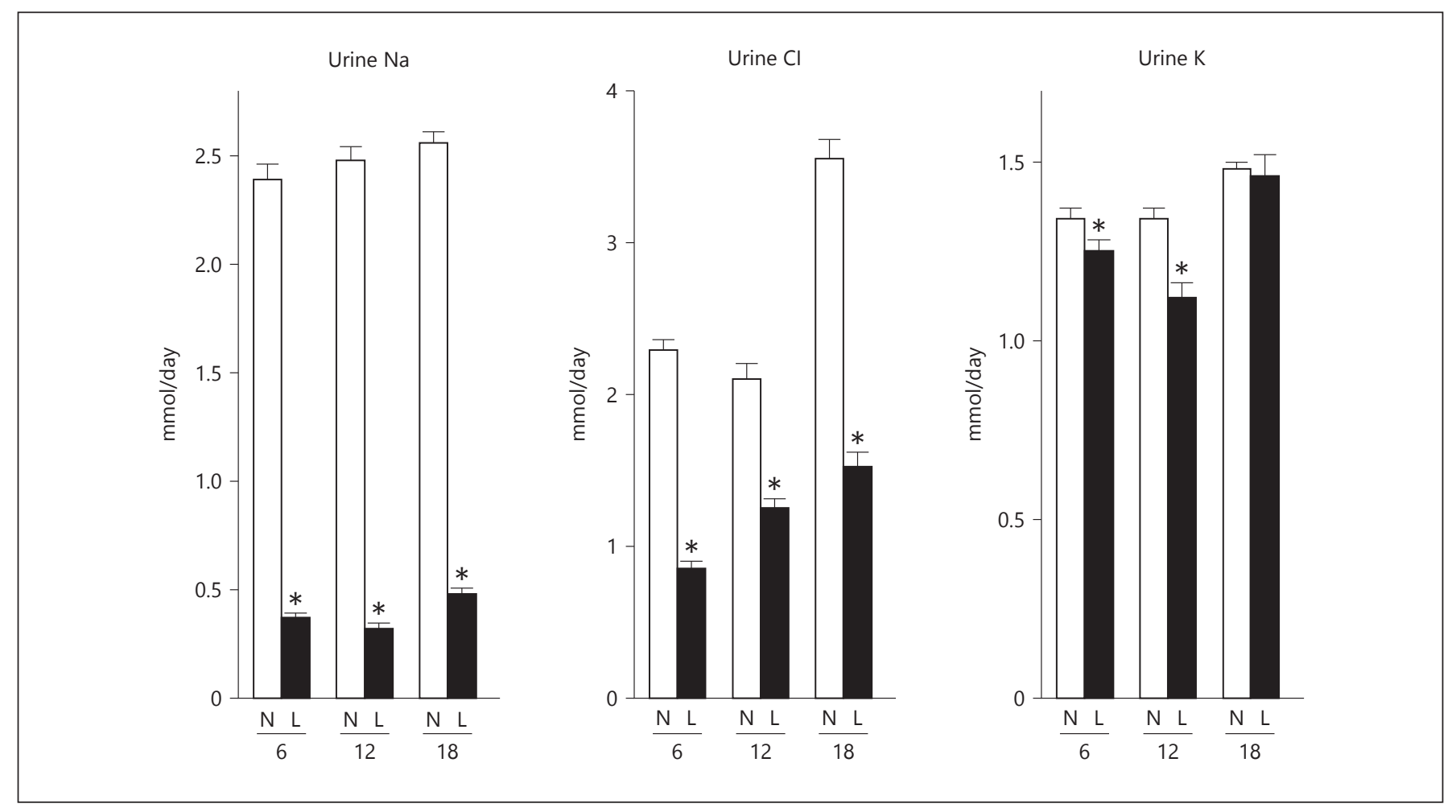

Fig. 2. Urine sodium $(\mathrm{Na})$, chloride $(\mathrm{Cl})$ and potassium $(\mathrm{K})$ excretion for GHS rats fed a normal $(\mathrm{N})$ or low $(\mathrm{L})$ sodium $(\mathrm{Na})$ diet. Urine was collected for four 24 -h periods at 6,12 , and 18 weeks from GHS rats to determine solute levels as described in the Concise Methods. Values are mean \pm SE for 11 rats in each group. $* p<0.05$ for $\mathrm{L}$ compared to $\mathrm{N}$ at the same time period.

\section{Bone Microarchitecture}

While there was no difference in cortical thickness, the femurs from rats fed the $\mathrm{LNaD}$ had significantly lower $\mathrm{AP}$ diameter when compared to $\mathrm{NNaD}$ (Table 2). MicroCT showed no significant differences between the 2 groups in the moment of inertia, porosity, or thickness of the cortical bone (data not shown). In the trabecular bone, microCT showed no significant differences in trabecular structural parameters, including percent BV, Tb.N, Tb.Th, and Tb.Sp (data not shown).

\section{Mechanical Properties}

There was significantly lower femoral stiffness in rats fed the LNaD; however, there was no difference in ultimate load, energy to fail, or Young's modulus (Table 2). Vertebral compression showed a trend toward lower yield displacement $(p=0.083)$ and lower stiffness $(0.075)$ with $\mathrm{LNaD}$ compared to $\mathrm{NNaD}$ (Table 2). There was also a trend toward lower yield strain $(p=0.079)$ and lower fail stress $(p=0.093)$ with $\mathrm{LNaD}$. Femoral-neck fracture showed no significant differences between $\mathrm{LNaD}$ and $\mathrm{NNaD}$ (data not shown). 


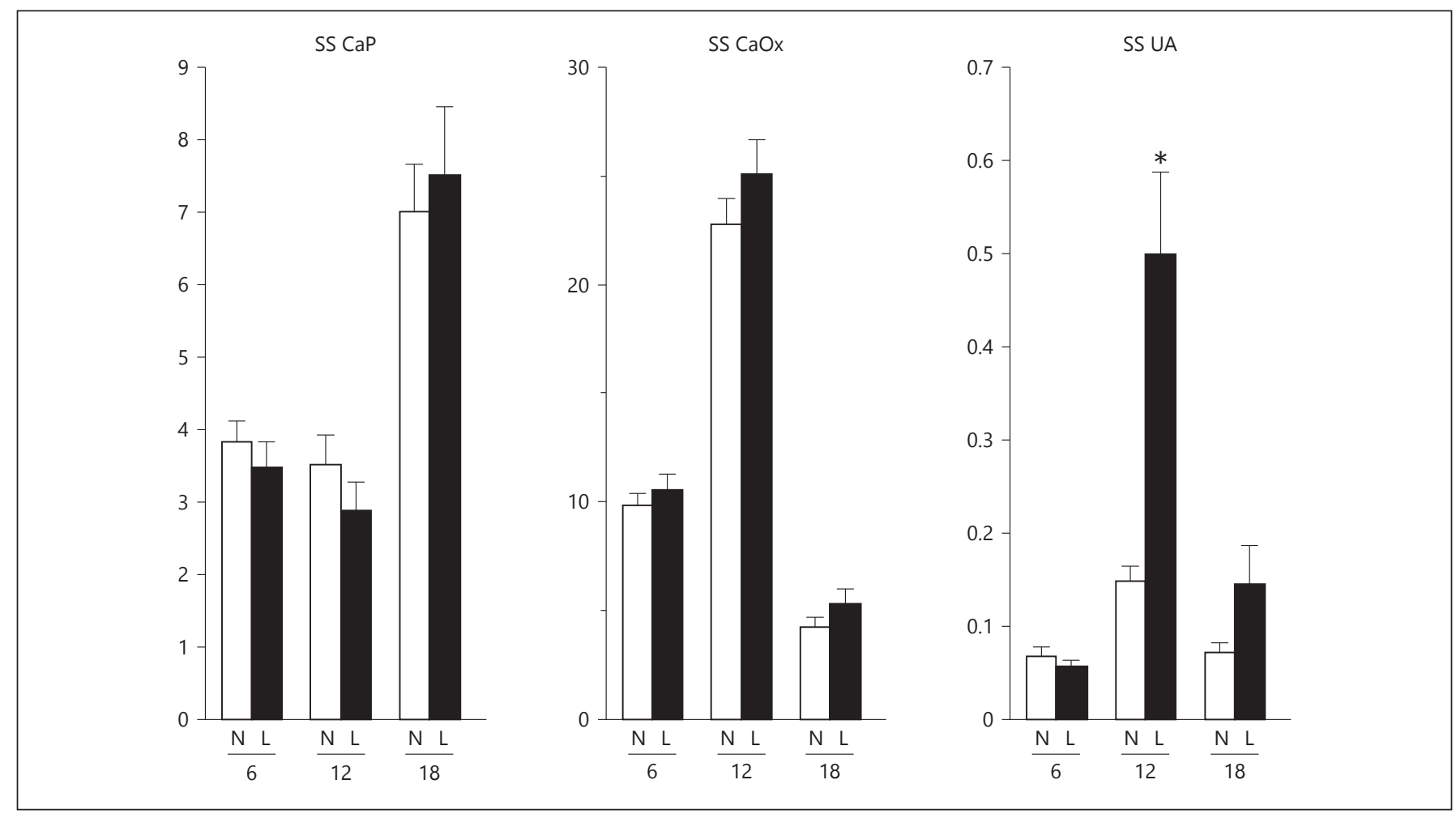

Fig. 3. Urine supersaturation (SS) for calcium phosphate $(\mathrm{CaP})$, calcium oxalate $(\mathrm{CaOx})$, and uric acid (UA) for GHS rats fed a normal $(\mathrm{N})$ or low $(\mathrm{L})$ sodium $(\mathrm{Na})$ diet. Urine was collected for four 24 -h periods at 6,12 , and 18 weeks to determine solute levels that were used to calculate relative SS as described in the Concise Methods. Values for relative SS are mean \pm SE $(n=11)$ and are unitless. $* p<0.05$ for $\mathrm{L}$ compared to $\mathrm{N}$ at the same time period.

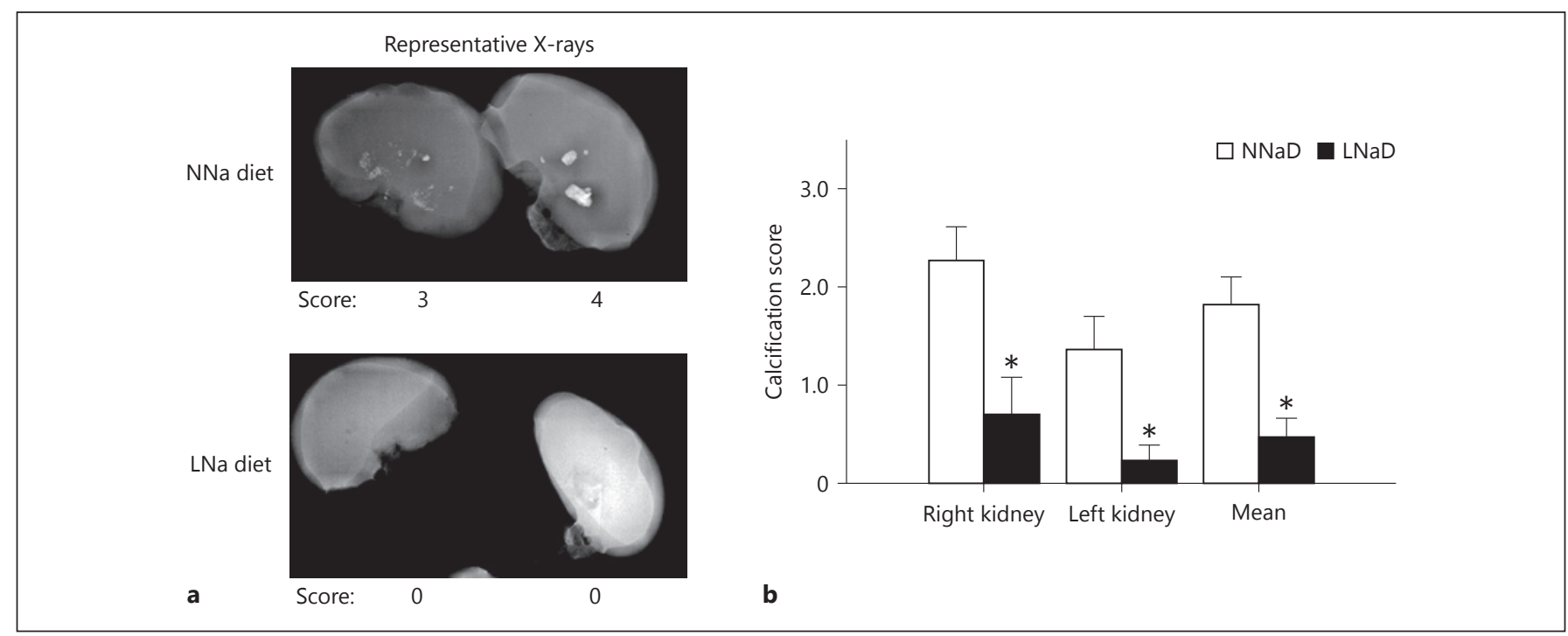

Fig. 4. Kidney stone formation at the conclusion of the 18 week study. At the end of the 18-week study, the extent of kidney stone formation was determined by blinded 3 observers as described in the Concise Methods. a Representative radiographs of kidneys on a normal $\mathrm{Na} \operatorname{diet}(\mathrm{NNaD})$ or a low $\mathrm{Na} \operatorname{diet}(\mathrm{LNaD})$. Calcification scores are provided as a reference. $\mathbf{b}$ Quantitation of stone formation and calcification in all GHS rats fed a $\mathrm{NNaD}$ or a LNaD. Values are mean \pm SEM $(n=11)$. ${ }^{*} p<0.05$ for $\mathrm{LNaD}$ compared to $\mathrm{NNaD}$. 


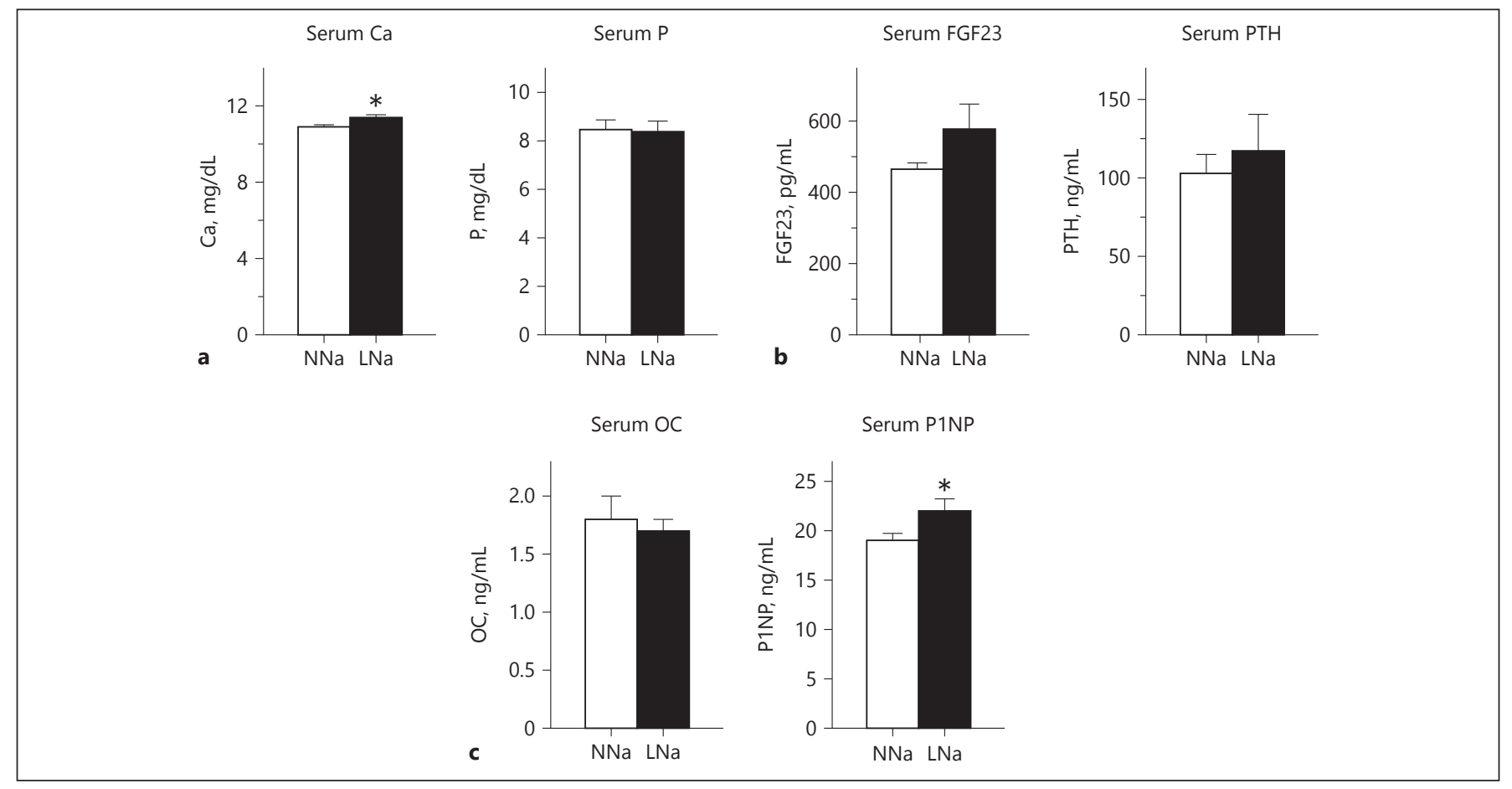

Fig. 5. Serum calcium (Ca), phosphorus $(\mathrm{P})$, fibroblast growth factor 23 (FGF23), parathyroid hormone (PTH), osteocalcin (OC), and amino terminal propeptide of type 1 collagen (P1NP) at the conclusion of the 18-week study. Serum levels were determined as described in the Concise Methods. a Serum Ca and P on normal

\section{Undecalcified Histomorphometry}

Static histomorphometry. Rats fed $\mathrm{LNaD}$ had significantly lower Tb.Sp compared to $\mathrm{NNaD}$ (Table 2). There was also a trend toward lower $\mathrm{Tb} . \mathrm{Th}(p=0.079)$ with $\mathrm{LNaD}$, as well as a trend toward a higher percent BS (BS/ $\mathrm{BV}, p=0.069)$ compared to $\mathrm{NNaD}$.

Dynamic histomorphometry. There were no significant differences in percent mineralized BS or BFR between $\mathrm{NNaD}$ and $\mathrm{LNaD}$ (Table 2).

\section{Decalcified Histology}

Based on tartrate-resistant acid phosphatase staining, there were no significant differences in bone resorption between $\mathrm{NNaD}$ and $\mathrm{LNaD}$. However, there was a trend toward a lower N.Oc per Oc.S $(p=0.077)$ with $\mathrm{LNaD}$ compared to $\mathrm{NNaD}$ (Table 2).

\section{Bone Mineralization}

BSE microscopy showed no significant differences in the mineralization of the bone between the 2 groups; however, there was a trend toward a higher peak grey level $(p=0.074)$ with $\mathrm{LNaD}$ compared to $\mathrm{NNaD}$ (Table 2$)$.
$\mathrm{Na}$ diet $(\mathrm{NNaD})$ compared to low $\mathrm{Na} \operatorname{diet}(\mathrm{LNaD}) ;$ (b) Serum FGF23 and PTH on NNaD compared to LNaD; (c) Serum OC and $\mathrm{P} 1 \mathrm{NP}$ on $\mathrm{NNaD}$ compared to $\mathrm{LNaD}$. Values are mean $\pm \mathrm{SEM}(n=$ 11). ${ }^{*} p<0.05$ for $\mathrm{LNaD}$ compared to $\mathrm{NNaD}$.

\section{Discussion}

GHS rats have alterations in Ca homeostasis including increased intestinal absorption, reduced renal tubular reabsorption, and increased bone resorption, similar to those of many patients with idiopathic IH [24]. Hypercalciuria in the GHS rats leads directly to stone formation as it does in humans $[1,37,39]$. GHS rats also have reduced $\mathrm{BMD}$, as do humans with nephrolithiasis, as well as lower trabecular volume and thickness compared to control Sprague-Dawley rats $[32,39]$. Previous studies on the effect of dietary $\mathrm{Na}$ intake, performed on humans with $\mathrm{IH}$, as well as normal rats $[48,49]$, demonstrate that increased dietary $\mathrm{Na}$ leads to increased hypercalciuria, as well as an increase in osteoporotic risk factors such as increased bone resorption and decreased BMD [48, 49]. In this study, we utilized GHS rats to determine the effect of a low $\mathrm{Na}$ diet, generally prescribed to help prevent recurrent stone formation $[11-16,50,51]$, on urine SS, stone formation, and bone quality.

Feeding the hypercalciuric GHS rats a low Na diet effectively reduced uCa excretion. However, in spite of an eight- 
Table 2. Bone parameters

\begin{tabular}{|c|c|c|}
\hline & $\mathrm{NNaD}$, mean $\pm \mathrm{SD}$ & $\mathrm{LNaD}$, mean $\pm \mathrm{SD}$ \\
\hline \multicolumn{3}{|l|}{$\mathrm{BMD}, \mathrm{g} / \mathrm{cm}^{3}$} \\
\hline Femoral cortical vBMD & $1.266 \pm 0.067$ & $1.206 \pm 0.058^{*}$ \\
\hline Vertebral trabecular vBMD & $0.704 \pm 0.077$ & $0.712 \pm 0.112$ \\
\hline \multicolumn{3}{|l|}{ Bone microachitecture, mm } \\
\hline Cortical thickness & $0.69 \pm 0.04$ & $0.69 \pm 0.02$ \\
\hline Anterior-posterior diameter & $3.60 \pm 0.12$ & $3.49 \pm 0.11^{*}$ \\
\hline \multicolumn{3}{|l|}{ Cortical mechanical properties } \\
\hline Stiffness, N/mm & $417.91 \pm 27.82$ & $377.58 \pm 45.27^{*}$ \\
\hline Ultimate load, $\mathrm{N}$ & $151.86 \pm 10.52$ & $146.55 \pm 10.79$ \\
\hline Energy to fail, $\mathrm{MPa}$ & $22.45 \pm 4.80$ & $21.02 \pm 5.04$ \\
\hline Young's modulus, GPa & $1.16 \pm 0.05$ & $1.12 \pm 0.15$ \\
\hline \multicolumn{3}{|l|}{ Vertebral compression } \\
\hline Stiffness, N/mm & $719.07 \pm 201.13$ & $583.67 \pm 80.20$ \\
\hline Failure stress, $\mathrm{MPa}$ & $40.58 \pm 6.30$ & $36.23 \pm 5.23$ \\
\hline Energy to fail, $\mathrm{MPa}$ & $2.76 \pm 0.95$ & $2.69 \pm 1.06$ \\
\hline Young's modulus & $740.22 \pm 225.56$ & $646.15 \pm 199.98$ \\
\hline \multicolumn{3}{|l|}{ Static histomorphometry } \\
\hline BS (BS/BV), \% & $32.31 \pm 2.54$ & $36.59 \pm 6.92$ \\
\hline $\mathrm{Tb} . \mathrm{Sp}, \mu \mathrm{m}$ & $0.29 \pm 0.05$ & $0.23 \pm 0.05^{*}$ \\
\hline Tb.N & $2.47 \pm 0.28$ & $2.67 \pm 0.40$ \\
\hline \multicolumn{3}{|l|}{ Dynamic histomorphometry } \\
\hline $\mathrm{MS} / \mathrm{BS}, \%$ & $23.31 \pm 6.06$ & $19.91 \pm 6.18$ \\
\hline Mineral apposition rate, $\mu \mathrm{m} /$ day & $1.96 \pm 0.31$ & $1.89 \pm 0.23$ \\
\hline $\mathrm{BFR} / \mathrm{BS}, \mu \mathrm{m} / \mathrm{day} / \mathrm{mm}$ & $0.02 \pm 0.01$ & $0.01 \pm 0.01$ \\
\hline $\mathrm{BFR} / \mathrm{BV}, \mu \mathrm{m} / \mathrm{day} / \mathrm{mm}^{2}$ & $0.61 \pm 0.30$ & $0.43 \pm 0.18$ \\
\hline \multicolumn{3}{|l|}{ Decalcified histology } \\
\hline Osteoclasts/OC.S, $1 / \mathrm{mm}$ & $19.10 \pm 4.35$ & $12.58 \pm 10.64$ \\
\hline \multicolumn{3}{|l|}{ Bone mineralization } \\
\hline Peak grey level & $169.30 \pm 8.78$ & $177.25 \pm 8.78$ \\
\hline
\end{tabular}

$* p<0.05$ compared to the NNaD.

$\mathrm{BMD}$, bone mineral density; $\mathrm{NNaD}$, normal $\mathrm{Na}$ diet; $\mathrm{LNaD}$, low $\mathrm{Na}$ diet; $\mathrm{BS}$, bone surface; $\mathrm{vBMD}$, volumetric bone mineral density; Tb.N, trabecular number; Tb.Sp, trabecular separation; OC.S, osteoclast surface; BFR, bone formation rate; $\mathrm{BS}$, bone surface; bone volume.

fold reduction in dietary $\mathrm{Na}$ intake and a fall in $\mathrm{uNa}$ of 2.09 $\mathrm{mmol}$, uCa fell by only $0.05 \mathrm{mmol}$. A similar decrease in uCa excretion was found in a previous study examining the effect of potassium citrate in GHS rats [44], while thiazides caused an even greater decrease in $\mathrm{uCa}$ [41] as well as improved BMD (20) compared to our findings in the current study [31]. The low $\mathrm{Na}$ diet also induced a reduction of $\mathrm{uP}$, $\mathrm{uCl}$, and $\mathrm{uK}$ but no differences in urine oxalate, citrate, ammonium, magnesium, $\mathrm{pH}$, or volume. The low Na diet-induced reductions in urine $\mathrm{Ca}$ and $\mathrm{P}$ excretion were insufficient to alter $\mathrm{SS}$ with respect to $\mathrm{CaP}$ or $\mathrm{CaOx}$, possibly due to the lower ionic strength of the urine leading to greater activity coefficients and therefore chemical activity of the critical ions. However, the GHS rats fed the low $\mathrm{Na}$ diet had a marked and unequivocal reduction in kidney stone for- mation. Why stone formation fell with no change in SS is not clear from this study. The urine SS with respect to the $\mathrm{CaP}$ solid phase, the type of stones formed by the GHS rats on this diet [36], exceeded 4.5 in both groups indicating that there was a marked driving force for $\mathrm{CaP}$ stone formation. It may be that alterations in dietary $\mathrm{Na}$ intake influence inhibitors and/or promoters of stone formation or crystalurothelial interactions. Further studies will be necessary to address this possibility. It has been suggested that, at least in humans, SS may not always be predictive of subsequent stone formation [52]; however, SS appears to be the best measure, available clinically, to predict stone recurrence [1]. It is possible that using a different program to estimate urine SS such as JESS [53] or LithoRisk [54] might bring better agreement between urine SS and stone formation. 
However, we have shown that EQUIL2 is an excellent predictor of CaP stone formation in GHS rats [37], and a recent publication demonstrated that a fall in SS calculated only by EQUIL2, and not JESS or LithoRisk, was significantly associated with a lower risk of stone recurrence in humans [55].

The GHS rats fed a low Na diet had a small, but significant, increase in serum $\mathrm{Ca}$, perhaps due to increasing passive proximal tubule $\mathrm{Ca}$ reabsorption, which follows $\mathrm{Na}$ and water reabsorption in this segment $[18,19]$. Additionally in the thick ascending limb of Henles' loop, increased $\mathrm{Na}$ reabsorption through the $\mathrm{Na} / \mathrm{K} / 2 \mathrm{Cl}$ transporter leads to increased $\mathrm{K}$ back diffusion into the lumen leading to an increased luminal positive charge, which drives Ca reabsorption through paracellular pathways [18]. In spite of the increase in serum $\mathrm{Ca}$, there were no changes in serum PTH or FGF23. Two markers of bone formation were studied, serum OC and P1NP. While there was no change in OC with low Na diet, P1NP increased, perhaps indicating increased bone formation in this group.

There were small but significant changes in bone quality in rats fed a low $\mathrm{Na}$ diet, including a significant reduction in femoral cortical vBMD and a reduction in AP diameter in the low, compared to the normal $\mathrm{Na}$, diet. GHS rats fed a low $\mathrm{Na}$ diet had a reduction in cortical stiffness, which indicates that their bone is more ductile and resistant to fracture. However, there was no difference in ultimate load, energy to fail or Young's modulus. As opposed to these changes in cortical mechanical properties, there were no significant differences in these parameters in the L6 vertebrae. Static and dynamic histomorphometry of tibiae of the GHS rats fed a low Na diet demonstrated decreased Tb.Sp as well as a trend toward increased percent BS. There was no difference between the 2 groups for osteoid or BFR; however, there was a trend toward a lower percentage of osteoclasts per Oc.S in the rats fed a low $\mathrm{Na}$ diet, which would result in decreased bone resorption.

Bone is a large reservoir for body $\mathrm{Na}$ [56]. Our results indicate that reducing dietary $\mathrm{Na}$ results in more ductile bone with lower cortical vBMD and decreased Tb.Sp. However, the changes in the bone parameters were modest and suggest that while the low $\mathrm{Na}$ diet reduces urine Ca excretion, which may improve bone quality and quantity, the reduction in dietary $\mathrm{Na}$ may have negative effects on bone density and quality that offset positive effects of this diet in reducing urine Ca excretion. However, the low $\mathrm{Na}$ diet did not appear to be detrimental to bone. As there were several trends toward improved trabecular bone with a low $\mathrm{Na}$ diet, it is possible that analysis of larger sample size over a longer time will help define more accurate comparisons.

Low Na Diet Reduces Stones in GHS Rats
In summary, using the GHS rats we found that a decrease in dietary $\mathrm{Na}$ resulted in a significant decrease in urine $\mathrm{Ca}$ excretion with no change in urine SS with respect to the Ca containing solid phases of kidney stones. Even so, there was a marked reduction in kidney stone formation in the GHS rats fed the low Na diet. This low $\mathrm{Na}$ diet did not appear to adversely alter the bone density and may improve it. If these results obtained in a model of hypercalciuric nephrolithiasis can be replicated in humans, it suggests that a low $\mathrm{Na}$ diet may be beneficial in preventing recurrent stone formation even if urine SS is not altered.

\section{Ethics Statement}

All animal experiments conform to internationally accepted standards and have been approved by the appropriate institutional review body at the University of Rochester.

\section{Disclosure Statement}

The authors have no competing financial interests and nothing to disclose.

\section{Funding Sources}

This work was supported by Grant RO1 DK075462 from the National Institutes of Health to D.A.B.

\section{Authors Contribution}

Conception and study design and interpretation of data: N.S.K., M.G., J.R.A., K.K.F., and D.A.B.; Drafting or revising the article: N.S.K., M.G., A.V.E., J.R.A., K.K.F., and D.A.B.; Providing intellectual content: N.S.K., M.G., A.V.E., J.R.A., K.K..F, M.H.K., F.R., I.G., and D.A.B.; Final approval of manuscript: N.S.K., M.G., A.V.E., J.R.A., K.K.F., M.H.K., F.R., I.G., and D.A.B.

\section{References}

1 Bushinsky DA, Coe FL, Moe OW: Nephrolithiasis; in Brenner BM (ed): The Kidney. Philadelphia, W.B. Saunders, 2012, vol 2, pp 1455-1507.

2 Bose A, Monk RD, Bushinsky DA: Kidney stones; in Melmed S, Polonsky KS, Larsen PR, Kronenberg HM (eds): Williams Textbook of Endocrinology. Philadelphia, Elsevier, 2016, pp 1365-1384.

3 Stechman MJ, Loh NY, Thakker RV: Genetics of hypercalciuric nephrolithiasis: renal stone disease. Ann N Y Acad Sci 2007;1116:461484 
4 Moe OW, Bushinsky DA: Genetic Hypercalciuria: A major risk factor in kidney stones; in Thakker RV, Whyte MP, Eisman JA, Igarashi $\mathrm{T}$ (eds): Genetics of Bone Biology and Skeletal Disease. London, Elsevier, 2013, pp 585-604.

5 Monico CG, Milliner DS: Genetic determinants of urolithiasis. Nat Rev Nephrol 2011;8: 151-162.

6 Pearle MS, Calhoun EA, Curhan GC; Urologic Diseases of America Project: Urologic diseases in America project: urolithiasis. J Urol 2005; 173:848-857.

7 Moe OW, Pearle MS, Sakhaee K: Pharmacotherapy of urolithiasis: evidence from clinical trials. Kidney Int 2011;79:385-392.

8 Park S, Pearle MS: Pathophysiology and management of calcium stones. Urol Clin North Am 2007;34:323-334.

9 Sakhaee K, Nicar M, Hill K, Pak CY: Contrasting effects of potassium citrate and sodium citrate therapies on urinary chemistries and crystallization of stone-forming salts. Kidney Int 1983;24:348-352.

10 Pearle MS, Goldfarb DS, Assimos DG, Curhan G, Denu-Ciocca CJ, Matlaga BR, Monga M, Penniston KL, Preminger GM, Turk TM, White JR: Medical management of kidney stones: AUA guideline. J Urol 2014; 192:316-324.

11 Pak CY: Medical management of urinary stoned. Nephron Clin Pract 2004;98:c49-c53.

12 Taylor EN, Fung TT, Curhan GC: DASHstyle diet associates with reduced risk for kidney stones. J Am Soc Nephrol 2009;20:22532259.

13 Yun SJ, Ha YS, Kim WT, Kim YJ, Lee SC, Kim WJ: Sodium restriction as initial conservative treatment for urinary stone disease. J Urol 2010;184:1372-1376.

14 Coe FL, Evan A, Worcester E: Pathophysiology-based treatment of idiopathic calcium kidney stones. Clin J Am Soc Nephrol 2011;6: 2083-2092.

15 Escribano J, Balaguer A, Roqué i Figuls M, Feliu A, Ferre N: Dietary interventions for preventing complications in idiopathic hypercalciuria. Cochrane Database Syst Rev 2014; 2:CD006022.

16 Vezzoli G, Dogliotti E, Terranegra A, Arcidiacono T, Macrina L, Tavecchia M, Pivari F, Mingione A, Brasacchio C, Nouvenne A, Meschi T, Cusi D, Spotti D, Montanari E, Soldati L: Dietary style and acid load in an Italian population of calcium kidney stone formers. Nutr Metab Cardiovasc Dis 2015;25:588-593.

17 Walser M: Calcium clearance as a function of sodium clearance in the dog. Am J Physiol 1961;200:1099-1104.

18 Friedman PA: Codependence of renal calcium and sodium transport. Annu Rev Physiol 1998;60:179-197.

19 Bindels RJ, Hoenderop JG, Biber J: Transport of calcium, magnesium, and phosphate; in Taal MW, Chertow GM, Marsden PA, Skorecki K, Yu ASL, Brenner BM (eds): The Kidney. Philadelphia, Elsevier, 2012, vol 1, pp 226-251.
20 Curhan GC, Willett WC, Speizer FE, Spiegelman D, Stampfer MJ: Comparison of dietary calcium with supplemental calcium and other nutrients as factors affecting the risk for kidney stones in women. Ann Intern Med 1997; 126:497-504.

21 Borghi L, Schianchi T, Meschi T, Guerra A, Allegri F, Maggiore U, Novarini A: Comparison of two diets for the prevention of recurrent stones in idiopathic hypercalciuria. $\mathrm{N}$ Engl J Med 2002;346:77-84.

22 Martini LA, Cuppari L, Colugnati FA, Sigulem DM, Szejnfeld VL, Schor N, Heilberg IP: High sodium chloride intake is associated with low bone density in calcium stone-forming patients. Clin Nephrol 2000;54:85-93.

23 Ticinesi A, Nouvenne A, Maalouf NM, Borghi L, Meschi T: Salt and nephrolithiasis. Nephrol Dial Transplant 2016;31:39-45.

24 Frick KK, Krieger NS, Bushinsky DA: Modeling hypercalciuria in the genetic hypercalciuric stone-forming rat. Curr Opin Nephrol Hypertens 2015;24:336-344.

25 Bushinsky DA, Favus MJ: Mechanism of hypercalciuria in genetic hypercalciuric rats. inherited defect in intestinal calcium transport. J Clin Invest 1988;82:1585-1591.

26 Li XQ, Tembe V, Horwitz GM, Bushinsky DA, Favus MJ: Increased intestinal vitamin D receptor in genetic hypercalciuric rats. A cause of intestinal calcium hyperabsorption. J Clin Invest 1993;91:661-667.

27 Krieger NS, Stathopoulos VM, Bushinsky DA: Increased sensitivity to $1,25(\mathrm{OH}) 2 \mathrm{D} 3$ in bone from genetic hypercalciuric rats. Am J Physiol 1996;271:C130-C135.

28 Tsuruoka S, Bushinsky DA, Schwartz GJ: Defective renal calcium reabsorption in genetic hypercalciuric rats. Kidney Int 1997;51:15401547.

29 Kim M, Sessler NE, Tembe V, Favus MJ, Bushinsky DA: Response of genetic hypercalciuric rats to a low calcium diet. Kidney Int 1993;43:189-196.

30 Yao J, Kathpalia P, Bushinsky DA, Favus MJ: Hyperresponsiveness of vitamin $D$ receptor gene expression to 1,25-dihydroxyvitamin D3. A new characteristic of genetic hypercalciuric stone-forming rats. J Clin Invest 1998; 101:2223-2232.

31 Bushinsky DA, Willett T, Asplin JR, Culbertson C, Che SP, Grynpas M: Chlorthalidone improves vertebral bone quality in genetic hypercalciuric stone-forming rats. J Bone Miner Res 2011;26:1904-1912.

32 Grynpas M, Waldman S, Holmyard D, Bushinsky DA: Genetic hypercalciuric stoneforming rats have a primary decrease in BMD and strength. J Bone Miner Res 2009;24: $1420-1426$.

33 Hoopes RR Jr, Middleton FA, Sen S, Hueber PA, Reid R, Bushinsky DA, Scheinman SJ: Isolation and confirmation of a calcium excretion quantitative trait locus on chromosome 1 in genetic hypercalciuric stone-forming congenic rats. J Am Soc Nephrol 2006;17: 1292-1304.
34 Bushinsky DA, Grynpas MD, Nilsson EL, Nakagawa Y, Coe FL: Stone formation in genetic hypercalciuric rats. Kidney Int 1995;48:17051713.

35 Bushinsky DA, Kim M, Sessler NE, Nakagawa Y, Coe FL: Increased urinary saturation and kidney calcium content in genetic hypercalciuric rats. Kidney Int 1994;45:58-65.

36 Asplin JR, Bushinsky DA, Singharetnam W, Riordon D, Parks JH, Coe FL: Relationship between supersaturation and crystal inhibition in hypercalciuric rats. Kidney Int 1997; 51:640-645.

37 Bushinsky DA, Parker WR, Asplin JR: Calcium phosphate supersaturation regulates stone formation in genetic hypercalciuric stone-forming rats. Kidney Int 2000;57:550560.

38 Bushinsky DA, Grynpas MD, Asplin JR: Effect of acidosis on urine supersaturation and stone formation in genetic hypercalciuric stone-forming rats. Kidney Int 2001;59:14151423.

39 Bushinsky DA, Asplin JR, Grynpas MD, Evan AP, Parker WR, Alexander KM, Coe FL: Calcium oxalate stone formation in genetic hypercalciuric stone-forming rats. Kidney Int 2002;61:975-987.

40 Evan AP, Bledsoe SB, Smith SB, Bushinsky DA: Calcium oxalate crystal localization and osteopontin immunostaining in genetic hypercalciuric stone-forming rats. Kidney Int 2004;65:154-161.

41 Bushinsky DA, Asplin JR: Thiazides reduce brushite, but not calcium oxalate, supersaturation, and stone formation in genetic hypercalciuric stone-forming rats. J Am Soc Nephrol 2005; 16:417-424.

42 Asplin JR, Donahue SE, Lindeman C, Michalenka A, Strutz KL, Bushinsky DA: Thiosulfate reduces calcium phosphate nephrolithiasis. J Am Soc Nephrol 2009;20:1246-1253.

43 Frick KK, Asplin JR, Favus MJ, Culbertson C, Krieger NS, Bushinsky DA: Increased biological response to $1,25(\mathrm{OH})(2) \mathrm{D}(3)$ in genetic hypercalciuric stone-forming rats. Am J Physiol Renal Physiol 2013;304:F718F726.

44 Krieger NS, Asplin JR, Frick KK, Granja I, Culbertson CD, Ng A, Grynpas MD, Bushinsky DA: Effect of potassium citrate on calcium phosphate stones in a model of hypercalciuria. J Am Soc Nephrol 2015;26:30013008.

45 Werness PG, Brown CM, Smith LH, Finlayson B: Equil2: a BASIC computer program for the calculation of urinary saturation. J Urol 1985;134:1242-1244.

46 Bushinsky DA, Bashir MA, Riordon DR, Nakagawa Y, Coe FL, Grynpas MD: Increased dietary oxalate does not increase urinary calcium oxalate saturation in hypercalciuric rats. Kidney Int 1999;55:602-612.

47 Bushinsky DA, Neumann KJ, Asplin J, Krieger NS: Alendronate decreases urine calcium and supersaturation in genetic hypercalciuric rats. Kidney Int 1999;55:234-243. 
48 Ryan LE, Ing SW: Idiopathic hypercalciuria and bone health. Curr Osteoporos Rep 2012; 10:286-295.

49 Chan AY, Poon P, Chan EL, Fung SL, Swaminathan R: The effect of high sodium intake on bone mineral content in rats fed a normal calcium or a low calcium diet. Osteoporos Int 1993;3:341-344.

50 He FJ, MacGregor GA: A comprehensive review on salt and health and current experience of worldwide salt reduction programmes. J Hum Hypertens 2008;23:363384.
51 Heilberg IP, Goldfarb DS: Optimum nutrition for kidney stone disease. Adv Chronic Kidney Dis 2013;20:165-174.

52 Rodgers AL: Urinary saturation: casual or causal risk factor in urolithiasis? BJU Int 2014; 114:104-110.

53 Rodgers A, Allie-Hamdulay S, Jackson G: Therapeutic action of citrate in urolithiasis explained by chemical speciation: increase in $\mathrm{pH}$ is the determinant factor. Nephrol Dial Transplant 2006;21:361-369.

54 Marangella M, Petrarulo M, Daniele PG, Sammartano S: LithoRisk: a software for cal- culating and visualising nephrolithiasis risk profiles. G Ital Nefrol 2002;19:693-698.

55 Ferraro PM, Ticinesi A, Meschi T, Rodgers A, Di Maio F, Fulignati P, Borghi L, Gambaro G: Short-term changes in urinary relative supersaturation predict recurrence of kidney stones: a tool to guide preventive measures in urolithiasis. J Urol 2018;200: 1082-1087.

56 Bushinsky DA, Chabala JM, Gavrilov KL, Levi-Setti R: Effects of in vivo metabolic acidosis on midcortical bone ion composition. Am J Physiol 1999;277:F813-F819. 